Methods Before beginning to strengthen the capabilities of road police GRSP undertakes a number of diagnostic assessments to identify barriers and opportunities to enforcement. Data collection methods and use are also strengthened to support police to undertake targeted enforcement interventions.

Results With predictive and strategic enforcement methods in place, road police are more effective in enforcing road safety related laws.

Conclusions To reduce the number of deaths and serious injuries on the world's roads there is a need to have strong road safety related policies in place, and for those policies to be enforced. Road police in low- and middle-income countries respond well to professional training on all aspects of enforcement.

\section{THE MOTORCYCLIST FATALITIES IN COLOMBIA FROM 2000-2014. A SERIOUS PUBLIC HEALTH ISSUE}

'Jorge Martín Rodríguez Hernández, ${ }^{2} J u l i o$ Cesar Campuzano, ${ }^{3}$ Cidronio AlvaberaHernández, ${ }^{1}$ Fredy Armindo Camelo. ${ }^{1}$ JaverianaUniversity, Colombia; ${ }^{2}$ Nacional Institute of Public Health of México; ${ }^{3}$ Mexican Institute of Social Security

\subsection{6/injuryprev-2016-042156.518}

Background Road traffic injuries and fatalities have increased in Colombia despite that 2011-2010 is the Decade of Road Safety Action. In the past few years mostly motorcyclists have been affected by fatality and trauma. This paper aims to describe the behaviour of motorcyclist fatality patterns in Colombia from 2000-2014.

Methods This longitudinal study used fatality records from the Colombian National Statistics Department and vehicle records from the Unified National Transit Registry and selected fatalities from International Classification of Diseases ICD-X V200 to ICD-X V299. The variables studied were year, age group, sex, department, and month of occurrence. A linear regression was used to identify the correlation between rates and fatalities, and the number of motorcycles during the period under study. The value $\mathrm{P}<0.05$ was used.

Results From 2000 to 2014 there was a near 100\% increase in the number of motorcyclist fatalities in Colombia; the occurrence rate increased from $3.5 / 100,000$ to $6.0 / 100,000$ inhabitants. $65.4 \%$ of the fatalities affected persons 15 to 34 years of age; $87 \%$ of whom were men. $55 \%$ of the fatalities took place in six provincial departments (Antioquia, Valle, Bogotá, Huila, Santander, and Meta). The months with the most casualties were July (8.7\%) and December (9.5\%). The rate and fatality behaviour can be explained by an increase in the number of vehicles of up to $92 \%$ ( $\mathrm{P}<0.001)$.

Conclusions Motorcyclist fatalities have become a serious public health issue. There are many determining factors associated with their occurrence: motorcyclists with little safety gear, lax granting of driver's licenses, weak processes for traffic law compliance (to control violation of laws and regulations, lack of safety gear, speeding, etc.), and inexpensive purchase plans for motorcycles. It is imperative to regulate motorcycle sales and to implement public policy that will prioritise compliance with national laws and regulations.

\section{INJURY PREVALENCE AND SAFETY HABITS OF MOTORCYCLE TAXI DRIVERS IN URBAN MOSHI, TANZANIA}

${ }^{1}$ Tuan-Dat $\vee$ Nguyen, ${ }^{2}$ Treasure Joelson, ${ }^{1}$ Joao Vissoci, ${ }^{2}$ Msafiri Pesambili, ${ }^{1}$ Michael Haglund, ${ }^{2}$ Mark Mvungi, 1,3 Catherine A Staton. 'Duke Global Health Institute, Duke University, Durham, NC, USA; ${ }^{2}$ Kilimanjaro Christian Medical Centre, Moshi, Tanzania; ${ }^{3}$ Division of Emergency Medicine, Duke University, Durham, NC, USA

\subsection{6/injuryprev-2016-042156.519}

Background Road traffic crashes are a major cause of global morbidity and mortality, disproportionately affecting low- and middle-income countries. Motorcycle taxi (boda-boda) drivers are particularly vulnerable because they have limited protection and safety equipment. This study characterises injury prevalence and safety habits amongst boda-boda drivers, and identifies intervention points to improve road safety.

Methods A prospective mixed methods interview and safety assessment was administered to 300 boda-boda drivers in urban Moshi, Tanzania. Participants were chosen randomly from 25 of 58 registered boda-boda stands and 2 of 31 unregistered stands. The survey was administered using a computerised, internet based survey tool (REDCAPS) and tablet computers. Data were analysed using $\mathrm{R}$, and a thematic analysis was performed and agreed upon by three investigators (MP, TN, CS).

Results Of the 148 participants (49.3\%) who had experienced a crash, $114(77.0 \%)$ sustained at least one injury. Only 27 of those injured (23.4\%) were hospitalised. 220 participants (73.3\%) reported consistent helmet usage despite the fact that 285 participants $(95.0 \%)$ agree that helmet usage reduces injury severity. Of the 280 helmets observed, 231 (82.5\%) were either damaged or fit improperly. A thematic analysis of boda-boda drivers' suggestions to increase road safety identified four intervention points: 1) roadway infrastructure and traffic regulation, 2) road user attitudes and safe driving behaviours, 3) education and training, and 4) law enforcement.

Conclusions The present study demonstrates the high prevalence of road traffic injuries amongst boda-boda drivers. The study identifies four intervention points that can be leveraged to increase overall road traffic safety. Unfortunately, while bodaboda drivers are aware of ways to improve safety, adherence to safety habits remains low. Successful interventions will bridge the gap between knowledge and practice of safety habits.

\section{SUMMATIVE PROCESS EVALUATION OF A DRIVER LICENSING SUPPORT PROGRAM IN REMOTE ABORIGINAL COMMUNITIES}

${ }^{1,2}$ Patricia Cullen, ${ }^{1,2}$ Anna Chevalier, ${ }^{1,2}$ Jake Byrne, ${ }^{1,3}$ Kate Hunter, ${ }^{2}$ Tom Gadsden, 1,2 Rebecca Ivers. 'The George Institute for Global Health; ' 2 ydney School of Public Health, University of Sydney, Australia; ${ }^{3}$ The Poche Centre for Indigenous Health, the University of Sydney

\subsection{6/injuryprev-2016-042156.520}

Background Aboriginal people in the Northern Territory (NT) have low rates of driver licensing, which is likely to contribute to high rates of transport-related injury, high rates of incarceration for regulatory driving offences and reduced access to employment, education and essential health services. The DriveSafe NT Remote program was implemented by the NT Government to increase driver licensing in remote communities. This evaluation reviews the program delivery, acceptability, implementation challenges and licensing outcomes. 
Methods A mixed-methods approach was used, incorporating program observation and key informant perspectives. Program data (collected April 2012 to June 2014) and de-identified licensing data from the NT Motor Vehicle Registry were analysed for trends in service delivery and licensing rates pre and postprogram.

Results Stakeholders reported that the program is meeting the needs of underserviced remote communities, and regarded the program as highly engaging and acceptable. There was a greater increase in new licences at intervention sites (Learner 24\% and Open licence 18\%) compared with other remote areas (Learner licence $13 \%$ and Open licence $8 \%$ ). There appeared to be a dose response relationship with greater licence outcomes at communities that received higher levels of program delivery.

Conclusions DriveSafe NT Remote is a Government delivered program that is acceptable to Aboriginal clients in remote NT communities, and is increasing driver licensing rates in these settings. The flexible delivery and culturally responsive approach should allow continuation of positive licensing outcomes.

\section{DOES AN ON-ROAD MOTORCYCLE COACHING PROGRAM REDUCE CRASHES IN NOVICE RIDERS? A RANDOMISED CONTROL TRIAL}

${ }^{1}$ Rebecca Q Ivers, ${ }^{1}$ Chika Sakashita, ${ }^{2}$ Teresa Senserrick, 1,3Jane Elkington, 'Serigne Lo, ${ }^{2}$ Soufiane Boufous, ${ }^{1,4}$ Liz de Rome. ${ }^{1}$ The George Institute for Global Health, University of Sydney, Australia; ${ }^{2}$ Transport and Road Safety Research, the University of NSW, Australia; ${ }^{3}$ New York University, Sydney, Australia; ${ }^{4}$ Neuroscience Research Australia

\subsection{6/injuryprev-2016-042156.521}

Background There is community demand for investment in motorcycle rider training programs but little evidence of its effectiveness in preventing crashes. This randomised trial of an onroad rider coaching program commissioned by VicRoads, the road authority for the State of Victoria, Australia, aimed to determine its effectiveness in reducing crashes in novice motorcycle riders.

Methods Between May 2010 and October 20122399 newlylicensed provisional riders were recruited in Victoria, Australia and completed a telephone interview before randomisation to intervention or control groups. Riders in the intervention group were offered an on-road motorcycle rider coaching program which involved pre-program activities, 4 hours riding and facilitated discussion in small groups with a riding coach. Outcome measures were collected for all participants via telephone interviews at 3 and 12 months after program delivery (or equivalent for controls), and via linkage to police-recorded crash and offence data. The primary outcome was a composite measure of police-recorded and self-reported crashes; secondary outcomes included traffic offences, near crashes, riding exposure, and riding behaviours and motivations.

Results Follow-up was $89 \%$ at 3 months and $88 \%$ at 12 months; $60 \%$ of the intervention group completed the program. Intention-to-treat analyses conducted in 2014 indicated no effect on crash risk at 3 months (adjusted OR 0.90, 95\% CI: 0.65-1.27) or 12 months (adjusted OR 1.00, 95\% CI: 0.78-1.29). Riders in the intervention group reported increased riding exposure, speeding behaviours and rider confidence.

Conclusions There was no evidence that this on-road motorcycle rider coaching program reduced the risk of crash, and we found an increase in crash-related risk factors. Given the absence of road safety benefits such programs should be considered a less promising strategy than other aspects of a safe system approach.

\section{EFFECTIVENESS OF MATERNITY DEPARTMENT INTERVENTION TO IMPROVE SAFETY KNOWLEDGE AND BEHAVIOUR OF CHILD PASSENGER}

${ }^{1}$ Xiangxiang Liu, ${ }^{2}$ Jingzhen Yang, ${ }^{3}$ Liping Li. ${ }^{1}$ Injury Prevention Research Centre, Medical College of Shantou University, China; ${ }^{2}$ The Research Institute at Nationwide Children's Hospital, USA; ${ }^{3}$ Injury Prevention Research Centre, Medical College of Shantou University, China

\subsection{6/injuryprev-2016-042156.522}

Background To test the effectiveness of maternity department intervention to improve knowledge of child passenger safety among newborn parents.

Methods A prospective experimental study which included three groups (one behaviour intervention group, one education intervention group and one control group) was conducted in the maternity department of two hospitals. Both intervention groups received a folded pamphlet of child passenger safety, a height chart and a standardised safety education during their hospital stay after giving birth. The behaviour intervention group received an additional free child car seat (CSS) and professional installation training at discharge. The control group received a pamphlet with no information on child passenger safety, a height chart or an education about infant care. Three months later, a phone interview was conducted among the participants in the three groups. Data on the child passenger safety knowledge, attitudes, and use of CSS were collected and evaluated before and after the intervention.

Results No significant difference observed in demographics among the three groups. There was a significant difference in CSS use among the three groups before and after the intervention $\left(\chi^{2}=19.6109, \mathrm{P}=0.0001\right)$. In the behaviour intervention group, the knowledge of safety belt $\left(\chi^{2}=13.1680, \mathrm{P}=0.0003\right)$, safety airbag $\left(\chi^{2}=51.0545, \mathrm{P}=0.0000\right)$, and CSS legislation $\left(\chi^{2}=10.0838, \mathrm{P}=0.0015\right)$ increased statistically after the intervention; and the drivers wearing safety belt increased from $90 \%$ to $100 \%\left(\chi^{2}=5.2525, \mathrm{P}=0.0219\right)$; answering phone without device reduced from $29 \%$ to $4 \%\left(\chi^{2}=11.8837, \mathrm{P}=0.0006\right)$. In the education group, the knowledge of safety airbag $\left(\chi^{2}\right.$ $=5.8667, \mathrm{P}=0.0154)$, and CSS $\left(\chi^{2}=5.4363, \mathrm{P}=0.0197\right)$ increased statistically after the intervention; and the drivers wearing safety belt increased from $66 \%$ to $86 \%\left(\chi^{2}=5.0661\right.$, $\mathrm{P}=0.0244)$. In the control group, except the statistically significant increase on the knowledge of CSS $\left(\chi^{2}=4.4308\right.$, $\mathrm{P}=0.0353$ ), there was no statistically changes in other study measures; and the drivers wearing safety belt increased from $75 \%$ to $95 \%\left(\chi^{2}=6.400, \mathrm{P}=0.0114\right)$.

Conclusion Lack of knowledge and poor perception contributed to low use of CSS. Interventions that combine a free CSS with child passenger safety education were effective in improving newborn parents' knowledge and use of CSS. The results of this study will be useful in development of effective interventions promoting child passenger safety.

\section{TRAFFIC-RELATED INJURIES AMONG THE YOUTH IN THE UNITED ARAB EMIRATES: A PROSPECTIVE TRAUMA REGISTRY-BASED STUDY}

${ }^{1}$ Michal Grivna, ${ }^{2}$ Hani $O$ Eid, ${ }^{2}$ Fikri M Abu-Zidan. ${ }^{1}$ Institute of Public Health, College of Medicine and Health Sciences, UAE University, Al Ain, UAE; ${ }^{2}$ Department of Surgery, College of Medicine and Health Sciences, UAE University, Al Ain, UAE

10.1136/injuryprev-2016-042156.523 